\title{
La liberté ne vaut que par les limites qu'on accepte de lui mettre
}

\section{Jean Martin}

Ancien membre de la Commission nationale d'éthique, membre de la rédaction

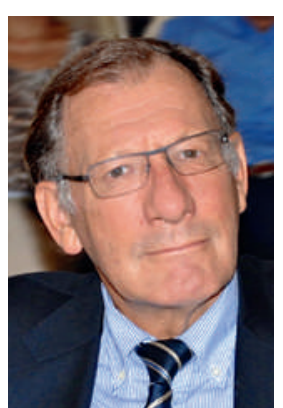

Je viens de faire un séjour aux Etat-Unis dans la famille d'un de nos enfants. Il y a quelques mois, le pays a été vivement interpellé par le meurtre à Ferguson, Missouri, d'un jeune Noir par un policier. Début mars, un rapport officiel a conclu à des pratiques manifestes de discrimination raciale par la police locale, dont le chef a dû démissionner le 11 mars. Au même moment, l'Université d'Oklahoma excluait deux étudiants qu'une vidéo montrait chantant des thèmes racistes rappelant l'époque de la ségrégation et des lynchages. Ainsi, s'il existe encore beaucoup de racisme ordinaire aux EtatUnis, illustré notamment par des chiffres montrant comment les tribunaux punissent très différemment les actes délictueux ou criminels selon qu'ils sont le fait d'un Blanc ou d'un Noir, certaines réactions correctrices appropriées interviennent; il y a lieu bien sûr de s'en féliciter. A relever qu'une certaine ambiance nostalgique avec des facettes racistes est confortée par la résistance du parti républicain (caricaturé comme celui des "vieux mâles blancs») à tout changement susceptible de promouvoir un pays plus équitable, divers et multiculturel, qui corresponde à sa réalité actuelle. A vrai dire, les attaques extrêmes dont est victime le Président Obama - et son épouse, souvent teintées de racisme, font douter de la raison (sanity) de plusieurs politiciens et journalistes.

A noter que les étudiants exclus de l'Université d'Oklahoma ont leurs soutiens, qui allèguent la garantie constitutionnelle de la liberté d'expression - dans la foulée de dérives de type libertarien encouragées par des milieux qui ne comptent pas l'argent qu'ils y consacrent. En Suisse aussi, la norme pénale antiraciste (art. 261bis de notre Code pénal), pourtant adoptée en vote populaire, est attaquée avec une motivation semblable. Or, l'invocation idéologique d'un «droit à faire tout et n'importe quoi» est un danger sérieux pour notre vivre ensemble. Je crois à la formule «La liberté ne vaut que par les limites qu'on accepte de lui mettre» (qui fait écho à «la liberté de l'un s'arrête là où commence celle de l'autre»). Peut-on contester que le respect de l'autre doit être, pour la vie en société, un impératif aussi fort qu'une conception maximaliste de la liberté? Ici on est amené à évoquer les assassinats odieux, à
Paris le 7 janvier, de journalistes de Charlie Hebdo. Il faut haïr de tels actes, je les hais. Mais je ne peux pas être d'accord avec les revendications dogmatiques d'un droit absolu à l'insulte ou au blasphème. D'abord, il y a de longue date des dispositions réprimant la calomnie ou la diffamation. Ensuite, une société qui voudrait ignorer, ou pire éradiquer, le fait religieux est condamnée à s'enfermer, comme la France actuellement, dans une laïcité ombrageuse, coercitive, réagissant de manière stridente dès que la facette religion de la vie apparaît en public. Intransigeance qui à vrai dire a des aspects bornés. Comment ne voit-on pas que les anathèmes laïcs lancés à des paroles ou actes qui ne sont que l'expression, non belliqueuse et non prosélyte, de ses convictions nie précisément cette liberté qu'on entend mettre sur un piédestal? Le principe prévalant en Suisse de la neutralité des pouvoirs publics en matière religieuse est beaucoup plus adéquat.

Il importe donc de promouvoir une convivialité marquée par le respect et par l'ouverture à comprendre l'autre et ses raisons. Etant entendu que, s'il y a lieu de chercher à comprendre, il ne peut être question de tout excuser et que certaines choses doivent être punissables - et punies!

La question est de savoir ce que nous voulons privilégier: une forme exacerbée de liberté individuelle ou un vivre-ensemble respectueux. A mon sens, la première option est une voie discutable, qui se révèlera une impasse source d'incessants conflits. Une civilité fondamentale (et le civisme dont nous sommes fiers) demande qu'on souligne que sa propre liberté n'inclut certainement pas de pouvoir insulter ad libitum autrui, ses croyances, ses caractères raciaux ou d'origine.

PS: Autre sujet, dont on reparlera : ce sont aussi des «libertaires» qui s'opposent à la dispensation raisonnable, comme cela se fait avec succès dans notre pays depuis plusieurs décennies, d'éducation sexuelle à l'école, sous une forme adaptée à l'âge. Une telle démarche a aussi des aspects discriminatoires: une partie des enfants ne reçoivent pas du tout à la maison les messages équilibrés, sains, nécessaires dans ce domaine et ils seraient alors désavantagés, et plus à risque d'erreurs ou malheurs ultérieurs, s'ils n'en entendent plus parler à l'école. 